\title{
Respiratory muscle activity in patients with COPD walking to exhaustion with and without pressure support
}

\author{
D. Kyroussis*, M.I. Polkey*, C-H. Hamnegård**, G.H. Mills***, M. Green***, J. Moxham*
}

Respiratory muscle activity in patients with COPD walking to exhaustion with and without pressure support. D. Kyroussis, M.I. Polkey, C-H. Hamnegard, G.H. Mills, M. Green, J. Moxham. (C) ERS Journals Ltd 2000.

ABSTRACT: The function of the diaphragm and other respiratory muscles during exercise in chronic obstructive pulmonary disease (COPD) remains controversial and few data exist regarding respiratory muscle pressure generation in this situation.

The inspiratory pressure/time products of the oesophageal and transdiaphragmatic pressure, and the expiratory gastric pressure/time product during exhaustive treadmill walking in 12 patients with severe COPD are reported. The effect of noninvasive positive pressure ventilation during treadmill exercise was also examined in a subgroup of patients $(n=6)$.

During free walking, the inspiratory pressure/time products rose early in the walk and then remained level until the patients were forced to stop because of intolerable dyspnoea. In contrast, the expiratory gastric pressure/time product increased progressively throughout the walk. When patients walked the same distance assisted by noninvasive positive pressure ventilation, a substantial reduction was observed in the inspiratory and expiratory pressure/time products throughout the walk. When patients walked with positive pressure ventilation for as long as they could, the pressure/time products observed at exercise cessation were lower than those observed during exercise cessation after free walking.

It is concluded that, in severe chronic obstructive pulmonary disease, inspiratory muscle pressure generation does not increase to meet the demands imposed by exhaustive exercise, whereas expiratory muscle pressure generation rises progressively. Inspiratory pressure support was shown to substantially unload all components of the respiratory muscle pump.

Eur Respir J 2000; 15: 649-655.

\author{
*Respiratory Muscle Laboratory, Kings \\ College and $* * *$ Respiratory Muscle Lab- \\ oratory, Royal Brompton Hospitals, Lon- \\ don, UK. **Dept of Pulmonary Medicine, \\ Sahlgrenska University Hospital, Gothen- \\ burg, Sweden.
}

Correspondence: D. Kyroussis YGEIA Hospital Dept of Thoracic Medicine 4, Erythrou Stavrou Maroussi 15123 Athens Greece Fax: 3016845089

Keywords: Abdominal muscles

chronic obstructive pulmonary disease diaphragm

exhaustive treadmill exercise

noninvasive ventilation

pressure/time product

Received: July 291998

Accepted after revision December 271999
Excessive inspiratory muscle loading has been postulated as a cause of exercise limitation in patients with severe chronic obstructive pulmonary disease (COPD) [14]. Other investigators consider that because compensatory adaptation occurs in the diaphragm of patients with COPD failure of transdiaphragmatic pressure $(P \mathrm{di})$ generation is not a clinically important problem [5]. Respiratory muscle recruitment during exercise in COPD has been previously examined during treadmill exercise $[6,7]$, but these studies examined only the amplitude of the pressure swings and did not address the impact of positive pressure ventilation (PPV). Respiratory muscle use has been studied by subsequent investigators using the model of cycle ergometry $[8,9]$. Thorough measurement of respiratory muscle pressure generation during exercise would determine whether exercise cessation coincided with failure of the respiratory muscle pump. Such measurements could also establish whether or not the diaphragm makes an important contribution to the demands placed upon the respiratory muscle pump by exercise in COPD.

Outside the laboratory, exercise limitation usually occurs in the context of constant rate walking. The magnitude and pattern of respiratory muscle recruitment during this type of exercise are therefore of great interest to both clin- ician and physiologist. The development of computerized data analysis has permitted the breath-by-breath quantification of the pressures generated by the respiratory muscles. Pressure/time product analysis has been used to examine respiratory muscle use in both normal subjects [10-12] and patients with COPD $[9,13,14]$. In the present communication, pressure/time product data for patients with severe COPD performing exhaustive treadmill exercise and also the effect of noninvasive positive pressure ventilation delivered via a facial mask are reported.

\section{Methods}

\section{Subject participation}

Twelve patients performed a series of constant-speed exhaustive treadmill walks as part of studies previously reported $[3,4,15]$. Six of these patients walked the same distance using noninvasive positive pressure ventilation. Additionally five patients performed positive pressure ventilation-assisted walks until exhaustion. All studies were approved by the Ethics Committee of Kings College Hospital and all patients gave their written informed consent to participation. 


\section{Exercise protocols}

For all subjects, the speed and gradient (if used) were individually chosen in preliminary sessions as the patients habitual "brisk" walk, such that intolerable dyspnoea would occur within 5-10 min [7]. These individual settings were maintained for all subsequent walks. Subjects were allowed to choose their own breathing pattern. The treadmill (Powerjog EG10, Sports Instruments, Birmingham, UK) was equipped with side guide rails, but subjects were prohibited from using these rails to support their body weight.

For free walks, patients were asked to walk on the treadmill until they were forced to stop because of intolerable dyspnoea. Strenuous verbal encouragement was given during all walks. Six subjects (Nos. 7-12) performed walks assisted by PPV delivered via a facial mask. They were asked to stop when they reached the distance walked unassisted (equidistant equal work rate walks). Five of these subjects (Nos. 7 and 9-12) also performed an exhaustive PPV-assisted walk; patient No. 8 was not available for this study due to worsening of the condition.

PPV was provided by a NIPPY ventilator (Friday Medical, London, UK) via a tightly fitting oronasal face mask. The NIPPY delivers triggered breaths in response to a fall in mask pressure ( $P$ mask) and also has a back-up frequency of mandatory breaths. It was anticipated that the respiratory frequency would increase during exercise and it was therefore decided to use the machine in the triggered mode. The trigger was set to be as sensitive as possible $(P$ mask -0.5 $\mathrm{cmH}_{2} \mathrm{O}$ ) and the back-up frequency as low as possible (expiratory time $6 \mathrm{~s}$ ). When using the NIPPY, the patient exhales to the atmosphere and there is no significant expiratory positive airway pressure. Before the PPV walk, the inspiratory time $(t \mathrm{I})$ and the level of PPV were adjusted to both optimize the subjective feeling of comfort and minimize the observed $P$ di. The investigators were permitted to make small adjustments of the PPV level and $t$ I during the walk in order to optimize patient comfort.

\section{Data acquisition}

Spirometric measurements were taken as the best of three efforts obtained using a bellows spirometer (Vitalograph, Buckinghamshire, UK). Lung volumes were determined using a constant-volume whole body plethysmograph (P.K. Morgan, Rainham, UK); the mean of three technically acceptable measurements was used.

Oesophageal $\left(P_{\text {oes }}\right)$ and gastric pressure $(P$ ga $)$ were recorded using conventionally placed balloon catheters (P.K. Morgan). The catheters were connected to differential pressure transducers (Validyne MP45; Validyne, Northridge, CA, USA), carrier amplifiers (P.K. Morgan), a 12-bit NBMIO-16 analogue/digital board (National Instruments, Austin, TX, USA) and a Macintosh Quadra Centris 650 personal computer (Apple Computer, Inc., Cupertino, CA, USA) running Labview ${ }^{\mathrm{TM}}$ software (National Instruments) sampling at $100 \mathrm{~Hz}$. Pdi was obtained on-line, by subtraction of $P$ oes from $P$ ga.

An index of inspiratory muscle strength was obtained by measuring $P_{\text {oes }}$ and $P$ di during a maximal sniff [16].

In order to measure minute ventilation during the free walk, the patients wore a tightly fitting face mask with a nonrebreathing two-way valve attached (Hans Rudolph 2600 series; Hans Rudolph, Kansas City, MO, USA). A pneumotachograph was placed in the expiratory limb of the circuit (Mercury electronics CS5; Mercury electronics Kilwinning, UK). It was chosen not to measure ventilation during PPV-assisted walks since the ventilator (NIPPY) compensates for mask leaks by delivering extra air, making such measurements difficult to interpret. Fingertip oxygen saturation and cardiac frequency were monitored throughout each walk (Ohmeda Biox 3700; Ohmeda, Boulder, CO, USA).

\section{Run selection}

Since most of the patients performed multiple runs, runs had to be selected for analysis. For the equidistant and exhaustive PPV-assisted runs, the free walks performed on the same day were used. In order not to introduce selection bias, for the remaining six subjects, the longest walk performed was analysed.

\section{Pressure/time product analysis}

Sections of the record with evidence of oesophageal peristalsis or coughing were discarded from the analysis. The discarded portions were $<5 \%$ of the total. The remainder of the record was analysed on a breath-by-breath basis using a modification of the LabView ${ }^{\mathrm{TM}}$ programme developed by the authors.

The inspiratory portion of the respiratory cycle was considered to run from end expiration to the beginning of expiration (defined as the zero points of expiratory flow). For PPV-assisted walks, a flow signal was not available and so the beginning of inspiration was taken as the point at which $P$ oes became subatmospheric and the end as the point at which $P$ oes became $>0$ (fig. 1 ).

The pressure/time products of $P$ oes, $P$ ga and $P$ di (PT $P$ oes, PTPga and PTPdi) were obtained by multiplying the area subtended by each trace by the respiratory frequency and had units of $\mathrm{cmH}_{2} \mathrm{O} \cdot \mathrm{s} \cdot \mathrm{min}^{-1}$. The baseline for PTPdi and PTPga was determined for each breath as the level observed at the start of inspiration and expiration respectively. The baseline for PTPoes was susceptible to increase as a result of abdominal muscle action; therefore, this level was individually determined for each patient and kept constant at the level observed at end expiration in the resting condition (fig. 1). All patients had a resting end-expiratory $P_{\text {oes }}(\mathrm{EE} P$ oes $)$ greater than or equal to atmospheric pressure.

The thoracic wall static recoil pressure $(P$ wst $)$ was not calculated. This is usually extrapolated from the $P$ wst/ volume curve of normal subjects, making the assumption that these relationships are linear within the tidal volume range [17]. The area measured for PT $P_{\text {oes compared to the }}$ area subtended by $P_{\text {oes }}$ and the $P$ wst/time curve during inpiration are only slightly different. Most importantly, this small difference is constant. Thus it cannot affect measurements of changes in muscle recruitment during exercise.

To allow comparison of the progression of respiratory muscle recruitment during exercise, the time during which each patient exercised was divided into ten epochs and the mean PTPdi, PTPoes and PTPga for each tenth calculated. 

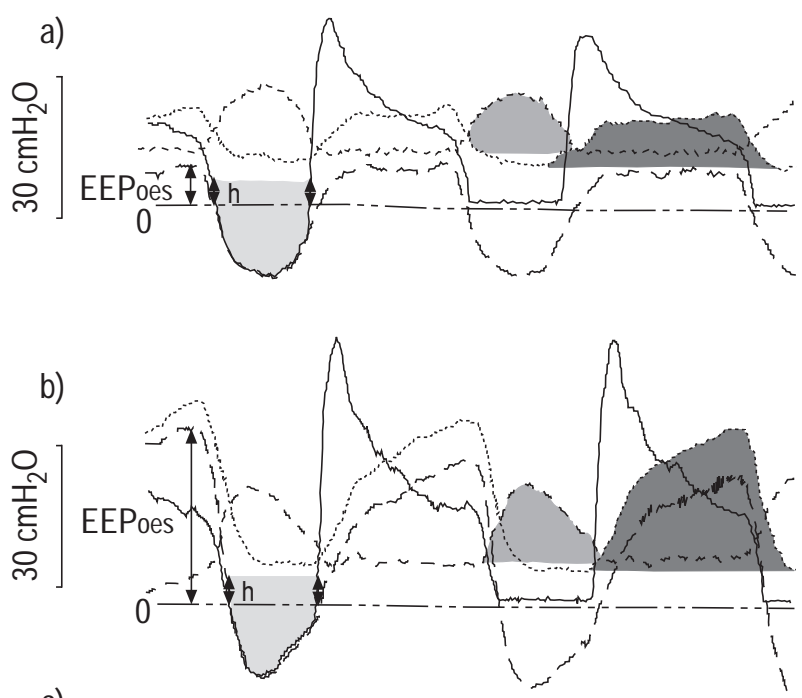

c)

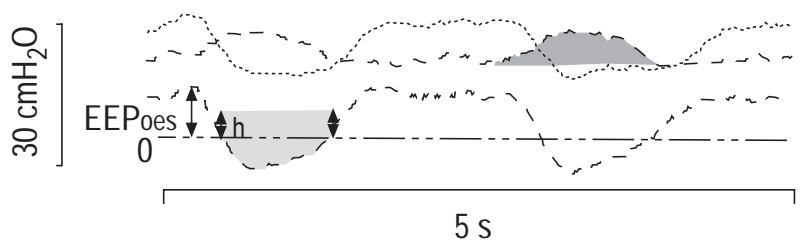

Fig. 1. - Representative pressure traces of a chronic obstructive pulmonary disease patient at: a) the beginning of a free walk; b) the end of a free walk, and c) the end of an exhaustive walk assisted by positive pressure ventilation $(-$ : flow; $\cdots \cdots \cdot$ : gastric pressure $(P$ ga $) ;---$ -: transdiaphragmatic pressure $(P \mathrm{di}) ;----$ : oesophageal pressure $\left(P_{\mathrm{oes}}\right) ; \quad$ : pressure/time produces (PTP) of $P_{\mathrm{di}}$; $:$ PTP of $P$ oes (PTPoes); : PTP of Pga (PTPga). At the beginning of the free walk (a), the end-expiratory $P_{\text {oes }}$ (EEPoes) was marginally higher than the EEPoes of the same patient measured prior to the walk during quiet breathing $(\mathrm{h})$. $\mathrm{h}$ was kept constant for all subsequent measurements of PTPoes of this patient. The EEPoes at the end of the free walk (b) was substantially increased, as was PTPga. During the positive pressure ventilationassisted walk (c), all PTPs were markedly reduced compared to the free walk.

\section{Statistics}

Results are expressed as mean \pm SEM unless otherwise specified. Statistics were computed using paired t-tests for comparisons involving all twelve subjects and Wilcoxon's signed-rank test for comparisons of the subgroup using inspiratory pressure support $(\mathrm{n}=6)$. The statistical package used was Statview 4.0 (Abacus Concepts, Berkeley, CA, USA); a p-value of $<0.05$ was taken as significant.

\section{Results}

Anthropometric, lung function and respiratory muscle strength data are shown in table 1 . The patients had severe airflow limitation (mean forced expiratory volume in one second $27 \%$ of the predicted value) with evidence of hyperinflation. Treadmill walking data are presented in table 2.

During free walking, the inspiratory PTPs (PTPoes and PTPdi) rose early in the walk and then remained level until exercise cessation (fig. 2). A fall in PTPdi was observed between the ninth and tenth epochs in 11 of the 12 patients, which, for the group, was statistically significant $(\mathrm{p}=$ 0.019).
The relative contribution of the diaphragm against the ribcage muscles was assessed by calculating the ratio PTPoes/PTPdi. Early in exercise, this ratio was close to unity for nine of the 12 subjects, indicating a predominant use of extradiaphragmatic muscles; in the remaining three a ratio of $\geq 2$ was observed, suggesting more marked ribcage predominance.

The pattern of abdominal muscle recruitment during exercise differed substantially from inspiratory muscle recruitment in that a progressive increase in PTPga was observed in all subjects throughout exercise, except during the transition from the ninth to the tenth epochs, when a small decline was observed (Ns) (fig. 3). In four subjects, however, the magnitude of this increase was small, whereas, in the remaining eight, a substantial increase was observed.

A progressive increase in minute ventilation was observed in all subjects until the penultimate epoch.

\section{Positive pressure ventilation-assisted walks}

Equidistant walks. PPV resulted in a decrease in both the PTPdi and PTPoes of the six patients who walked with and without PPV (fig. 4). The use of PPV prevented the progressive increase in PTPga (fig. 5). Interestingly, at the start of exercise there was a trend for PTPga to be greater during PPV-assisted exercise than during the free walk $(\mathrm{p}=0.11)$.

Exhaustive positive pressure ventilation walks. Five subjects were studied during exhaustive PPV-assisted walking. The PTPoes and PTPdi at the time of exercise cessation did not reach the levels seen at exercise cessation during free walking (table 3). Subjects with a marked rise in PTPga during free walking (Nos. 7 and 12) demonstrated substantial abdominal muscle unloading with PPV. Conversely, the others, with mild expiratory muscle use during free walking showed relatively little change with PPV. The two subjects with the biggest increase in walk time were those with marked expiratory muscle use during the free walk.

\section{Discussion}

The present data show that, in patients with severe COPD performing exhaustive steady-state treadmill exercise, the absolute pressures generated by the inspiratory muscles stop increasing well before exercise termination; this effect is particularly marked for the diaphragm. In contrast, abdominal muscle pressure generation and minute ventilation continue to increase until the point of exercise limitation, although there is considerable variation in the extent of abdominal muscle recruitment. The use of PPV caused a marked reduction in both expiratory and inspiratory pressure generation. The pressures generated at the end of exhaustive PPV-assisted walking were less than those observed at the end of exhaustive free walking. Further discussion of the significance of the findings follows a critique of the method. 
Table 1. - Anthropometric, spirometric and respiratory muscle strength data of participants

\begin{tabular}{|c|c|c|c|c|c|c|c|c|c|c|c|}
\hline \multirow[b]{2}{*}{$\begin{array}{l}\text { Patient } \\
\text { No. }\end{array}$} & \multirow[b]{2}{*}{$\begin{array}{l}\text { Age } \\
\text { yrs }\end{array}$} & \multirow[b]{2}{*}{ Sex } & \multirow[b]{2}{*}{ Height } & \multicolumn{2}{|c|}{ FEV1 } & \multicolumn{2}{|c|}{ TLC } & \multicolumn{2}{|c|}{ TGV } & \multirow[b]{2}{*}{$\begin{array}{l}\mathrm{Sn} P_{\text {oes }} \\
\mathrm{cmH}_{2} \mathrm{O}\end{array}$} & \multirow[b]{2}{*}{$\begin{array}{c}\mathrm{Sn} P \mathrm{di} \\
\mathrm{cmH}_{2} \mathrm{O}\end{array}$} \\
\hline & & & & $\mathrm{L}$ & $\begin{array}{c}\% \\
\text { pred }\end{array}$ & $\mathrm{L}$ & $\begin{array}{c}\% \\
\text { pred }\end{array}$ & $\mathrm{L}$ & $\begin{array}{c}\% \\
\text { pred }\end{array}$ & & \\
\hline 1 & 63 & $\mathrm{~F}$ & 1.58 & 1.3 & 53 & - & - & - & - & 56 & 68 \\
\hline 2 & 72 & M & 1.62 & 0.9 & 37 & 5.80 & 99 & 4.64 & 139 & 58 & 87 \\
\hline 3 & 72 & M & 1.62 & 0.9 & 38 & 5.40 & 110 & 3.53 & 105 & 56 & 61 \\
\hline 4 & 62 & M & 1.54 & 0.6 & 31 & 4.75 & 109 & 4.12 & 164 & 73 & 86 \\
\hline 5 & 67 & M & 1.70 & 0.7 & 24 & 8.90 & 164 & 6.55 & 188 & 58 & 90 \\
\hline 6 & 60 & M & 1.64 & 0.4 & 14 & 8.38 & 139 & 6.91 & 211 & 42 & 60 \\
\hline 7 & 63 & M & 1.63 & 0.5 & 18 & 7.30 & 136 & 4.90 & 140 & 72 & 110 \\
\hline 8 & 53 & M & 1.66 & 0.6 & 19 & 7.70 & 124 & 6.20 & 190 & 55 & 67 \\
\hline 9 & 73 & M & 1.68 & 0.7 & 27 & 7.50 & 142 & 5.40 & 153 & 60 & 78 \\
\hline 10 & 53 & M & 1.68 & 0.5 & 15 & 8.00 & 144 & 5.87 & 177 & 61 & 80 \\
\hline 11 & 69 & M & 1.72 & 0.8 & 28 & 8.50 & 134 & 6.40 & 193 & 60 & 69 \\
\hline 12 & 66 & M & 1.73 & 0.6 & 20 & 6.10 & 110 & 4.50 & 127 & 87 & 93 \\
\hline Mean \pm SD & $64.4 \pm 6.8$ & & $1.7 \pm 0.1$ & $0.7 \pm 0.2$ & $27 \pm 11$ & $7.1 \pm 1.4$ & $128 \pm 20$ & $5.4 \pm 1.1$ & $162 \pm 33$ & $62 \pm 11$ & $79 \pm 15$ \\
\hline
\end{tabular}

FEV1: forced expiratory volume in one second; TLC: total lung capacity; TGV: thoracic gas volume; SnPoes: oesophageal pressure measured during a sniff manoeuvre; SnPdi: transdiaphragmatic pressure measured during a sniff manoeuvre; F: female; M: male.

\section{Critique of the method}

What is the relevance of pressure/time product analysis? The PTPoes, PTPdi and PTPga have been used to assess respiratory muscle activity $[8,9,13,18]$, and correlate well with measurements of the oxygen consumption of contracting respiratory muscles [19]. Alternative approaches include assessment of electromyographic activity [20,21] or the Poes:Pga ratio $[22,23]$. It should be noted that the PTP is not synonymous with work, which is the product of pressure and flow.

Definition of inspiration and expiration and baseline. Accurate definition and determination of the crossover between inspiration and expiration are critical to valid quantification of pressure generation. Previous investigators have, as in the current study, used the flow signal $[8,9]$. For the PPV-assisted runs, inspiration was considered to have started once $P$ oes was subatmospheric on the assumption that airflow would occur in this situation. However, positive end-expiratory pressure was a frequent finding; thus inspiratory muscle activity must start before airflow occurs. In order to include muscle activity that occurred before airflow started, PTPoes was calculated as the area subtended by $P_{\text {oes }}$ and a horizontal line at the level of the (EEPoes) of each patient measured during quiet breathing before the exhaustive walk. This level was kept constant, assuming that changes in EEPoes during exercise were mainly the result of abdominal muscle recruitment (fig. $1)$.

\section{Significance of the findings}

Free walking. The basic observation made in the patients in the present study was that, during unassisted constant rate walking, minute ventilation and expiratory muscle pressure generation continued to increase until the point of exercise cessation, but that the rise in global inspiratory muscle, and particularly $P$ di generation, levelled off early in the walk. In normal subjects, when ventilatory demands increase, abdominal muscles contract to assist diaphragmatic and inspiratory muscle function. Severely obstructed patients are frequently flow-limited even during quiet breathing and

Table 2. - Treadmill walking characteristics

\begin{tabular}{|c|c|c|c|c|c|c|c|c|c|c|c|}
\hline \multirow[b]{2}{*}{$\begin{array}{l}\text { Patient } \\
\text { No }\end{array}$} & \multirow[b]{2}{*}{$\begin{array}{l}\text { Speed } \\
\mathrm{km} \cdot \mathrm{h}^{-1}\end{array}$} & \multirow[b]{2}{*}{$\begin{array}{c}\text { Time } \\
\mathrm{s}\end{array}$} & \multirow[b]{2}{*}{$\begin{array}{c}\text { Distance } \\
\mathrm{m}\end{array}$} & \multicolumn{2}{|l|}{$f \mathrm{c}$} & \multicolumn{2}{|c|}{$\mathrm{S}_{\mathrm{a}, \mathrm{O}_{2}} \%$} & \multicolumn{2}{|c|}{$f \mathrm{R}$} & \multicolumn{2}{|c|}{$t \mathrm{I} / t$ tot } \\
\hline & & & & beats $\cdot \min ^{-1} *$ & $\% \max$ & Start & End & Start & End & Start & End \\
\hline 1 & 1.9 & 285 & 150 & 95 & 62 & 93 & 95 & 22 & 26 & 0.55 & 0.47 \\
\hline 2 & 3.0 & 260 & 223 & 115 & 75 & 88 & 77 & 20 & 28 & 0.51 & 0.47 \\
\hline 3 & 1.5 & 354 & 148 & 101 & 66 & 88 & 75 & 25 & 30 & 0.40 & 0.43 \\
\hline 4 & 2.0 & 248 & 140 & 136 & 89 & 98 & 88 & 23 & 26 & 0.32 & 0.32 \\
\hline 5 & 1.7 & 306 & 144 & 119 & 78 & 89 & 83 & 34 & 31 & 0.32 & 0.27 \\
\hline 6 & 1.0 & 54 & 16 & NA & NA & NA & NA & 24 & 24 & 0.25 & 0.27 \\
\hline 7 & 1.5 & 340 & 143 & 120 & 78 & 89 & 77 & 18 & 32 & 0.28 & 0.26 \\
\hline 8 & 1.5 & 354 & 169 & 125 & 82 & 96 & 84 & 14 & 24 & 0.32 & 0.29 \\
\hline 9 & 1.6 & 549 & 244 & 107 & 70 & 91 & 87 & 22 & 24 & 0.31 & 0.26 \\
\hline 10 & 1.0 & 590 & 161 & 139 & 91 & 94 & 89 & 12 & 20 & 0.26 & 0.28 \\
\hline 11 & 1.8 & 419 & 215 & 78 & 51 & 95 & 91 & 10 & 14 & 0.29 & 0.29 \\
\hline 12 & 1.2 & 304 & 102 & 109 & 71 & 94 & 88 & 26 & 28 & 0.36 & 0.37 \\
\hline Mean \pm SD & $1.64 \pm 0.54$ & $339 \pm 140$ & $155 \pm 60$ & $113 \pm 18$ & $74 \pm 12$ & $92 \pm 3$ & $85 \pm 6$ & $21 \pm 7$ & $26 \pm 5$ & $0.35 \pm 0.09$ & $0.33 \pm 0.08$ \\
\hline
\end{tabular}

*: at the end of exercise. $f \mathrm{c}$ : cardiac frequency; $S_{\mathrm{a}, \mathrm{O}_{2}}$ : arterial oxygen saturation; $f \mathrm{R}$ : respiratory frequency; $t \mathrm{r}$ : inspiratory time; $t$ tot: duration of total breathing cycle; max: maximum; NA: not available. 


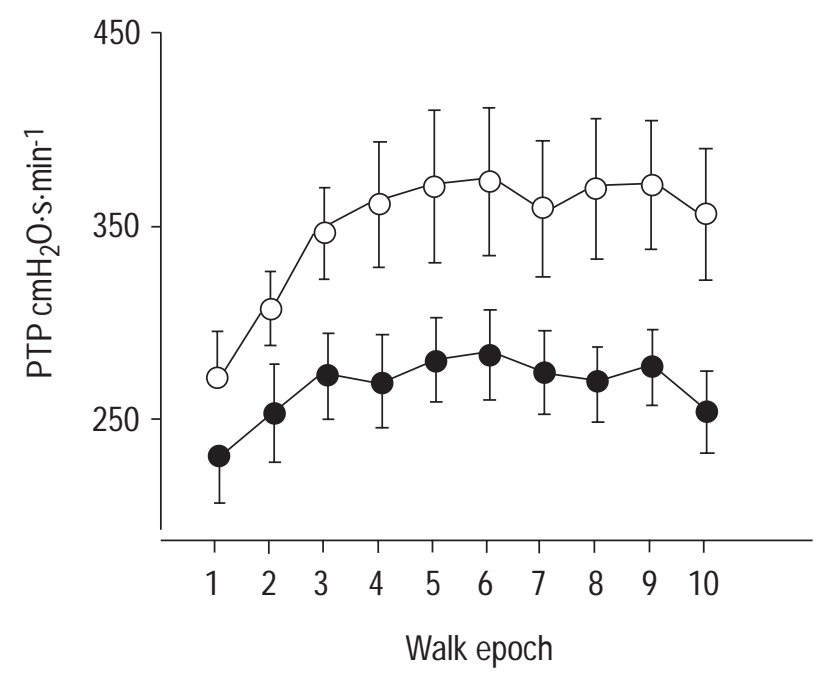

Fig. 2. - Progression of mean pressure/time product (PTP) of oesophageal pressure $(O)$ and PTP of transdiaphragmatic pressure (O) by $10 \%$ epoch of walk duration for the free exhaustive walk (12 subjects). Data are presented as mean \pm SEM.

cannot therefore increase expiratory flow. Similarly, as hyperinflation is exaggerated during exercise in COPD, the time available for expiration does not permit lowering of the lung volume to a level at which elastic and gravitational energy could be stored for the next inspiration. Finally, optimization of diaphragm function by lengthening muscle fibres could only happen if abdominal muscle contraction overlapped the beginning of the inspiratory phase, for which, to date, there is no evidence. It is, therefore, not clear what purpose the recruitment of abdominal muscles could serve during exercise in COPD patients. If abdominal muscle recruitment does not assist inspiratory muscle function then, logically, it should be detrimental, both because of energetic considerations and because it might give rise to dyspnoea [24]. In the present study, the magnitude of abdominal muscle recruitment was variable between subjects; this observation is of interest if one accepts the view that abdominal muscle use represents a vestigial reflex which cannot be suppressed [20].

Since PTPoes and PTPdi were shown to reach a plateau early in exercise, and if expiratory muscle activity cannot

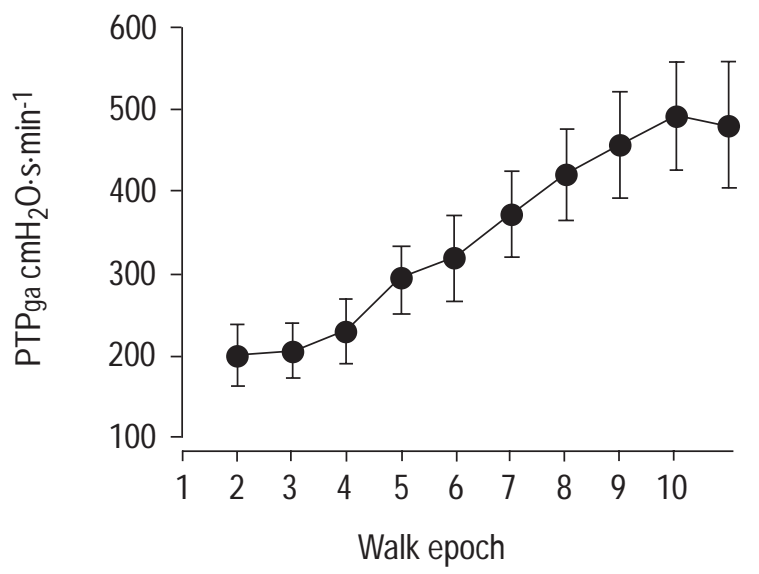

Fig. 3. - Progression of mean pressure/time product of gastric pressure (PTPga) by $10 \%$ epoch of walk duration for the free exhaustive walk (12 subjects). Data are presented as mean \pm SEM.
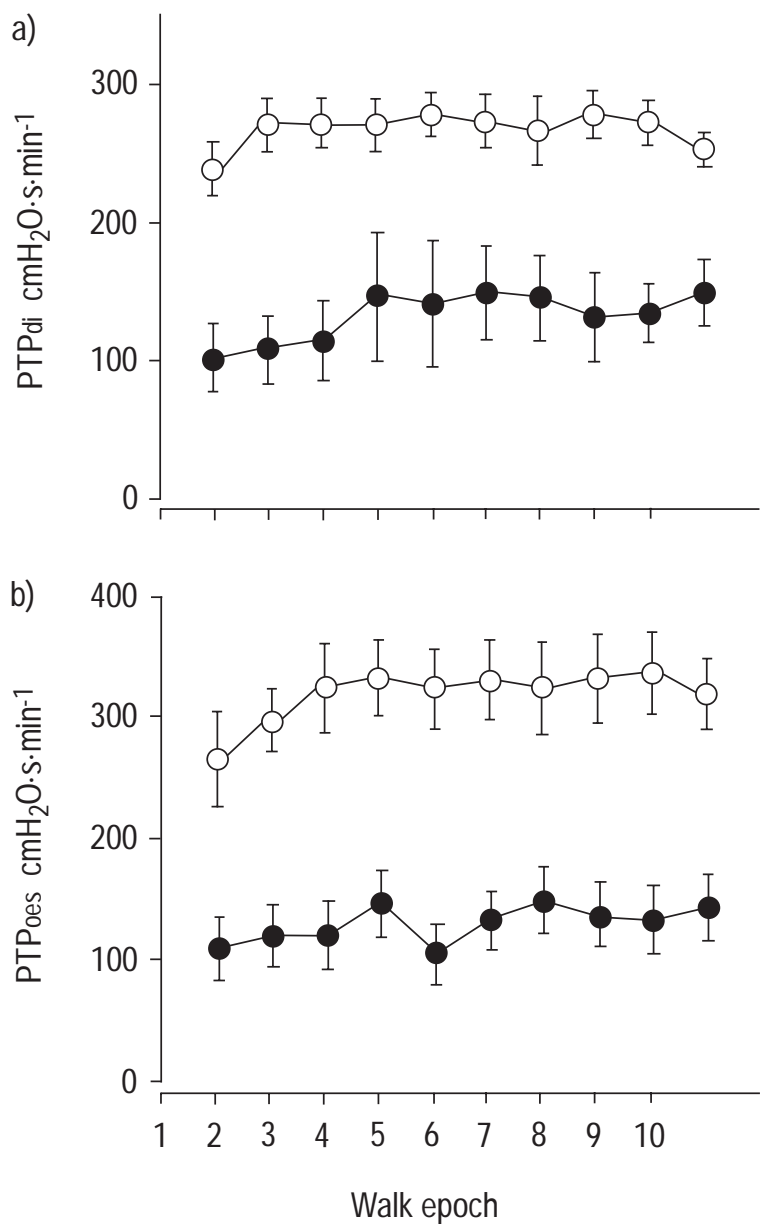

Fig. 4. - Progression of mean: a) pressure/time product (PTP) of transdiaphragmatic pressure (PTPdi); and b) PTP of oesophageal pressure (PTPoes) by $10 \%$ epoch of walk duration during free $(\bigcirc)$ and equidistant positive pressure ventilation-assisted walking (O) (six subjects). Data are presented as mean \pm SEM.

increase minute ventilation, the present data require an alternative mechanism whereby minute ventilation can be increased without increased pressure from the respiratory muscles. The obvious candidate for this is progressive dynamic hyperinflation. Dynamic hyperinflation would, despite increased neural drive [21], give the appearance of a levelling off of inspiratory muscle pressure generation by virtue of the length/tension relationship [25]. Since the maximum expiratory flow/volume curve is not changed during exercise in COPD [26], increased minute ventilation requires movement of the end-expiratory lung volume closer to the total lung capacity. Thus the present data predict that end-expiratory lung volume rises progressively during exercise in COPD; this hypothesis has not, to the authors knowledge, been examined in detail during exercise in COPD patients performing treadmill exercise. However, this pattern has been recorded during incremental cycle ergometry [27, 28]. Dynamic hyperinflation, therefore, seems a reasonable explanation for the present data; if this is the case, the data are of interest because they indicate that, in a model which closely corresponds to daily activities, the loss of $P$ di- and global inspiratory muscle pressure-generating capacity incurred is profound. 


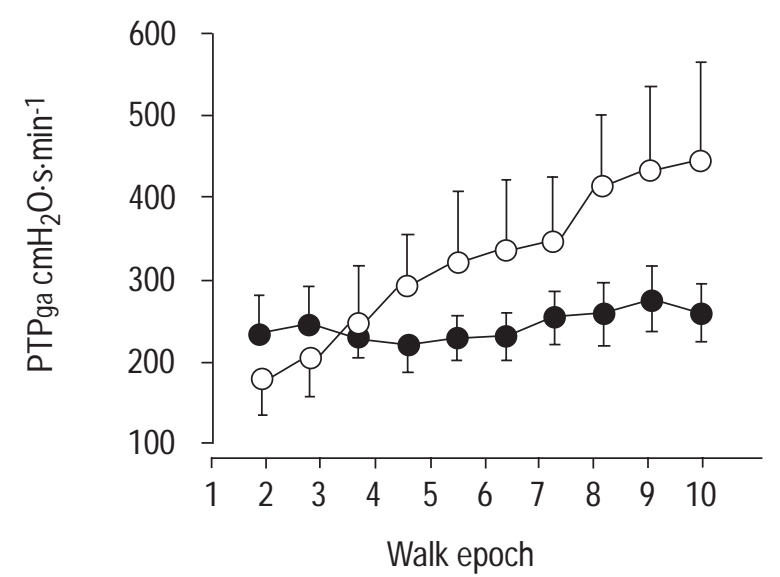

Fig. 5. - Progression of pressure time product of gastric pressure (PTPga) by $10 \%$ epoch of walk duration during free $(O)$ and equidistant positive pressure ventilation-assisted walking (O) (six subjects). Data are presented as mean \pm SEM.

The ratio PTPoes/PTPdi was high and tended to increase during the walk, in keeping with a reduced diaphragmatic contribution compared to the ribcage musculature.

The present data show a downturn between the ninth and tenth exercise epochs in PTPdi and PTPoes. This could be interpreted as evidence of diaphragmatic and/or inspiratory muscle fatigue. An alternative explanation for this phenomenon could be that either the precipitant of exercise cessation is a further, intolerable, increase in dynamic hyperinflation or the discomfort in maintaining inspiratory pressure generation was intolerable.

Assisted walks. Equidistant ventilation. The reduction in inspiratory pressure/time products observed during PPV compared with free walking was proportionately the same in all subjects. PTPga, which progressively increased during free walking, remained constant during PPV-assisted walking. These data indicate a general reduction in central drive, due presumably to the unloading effect of PPV [4], rather than a specific adaptation of the system to PPV. It is of interest that with PPV the initial PTPga was slightly greater than during free walking. The most probable explanation for this is that the expiratory limb of the circuit, although open to the atmosphere, presents a small resistance.

Exhaustive positive pressure ventilation-assisted exercise. The purpose of this part of the study was to establish whether or not during prolonged PPV-assisted walking respiratory muscle recruitment would reach the levels observed during free walking; as shown in table 3 , this did not occur. This observation argues against the concept that exercise limitation in this context occurs as a result of a failure of the patient/ventilator interaction [29] and instead points to a physiological process. This could either be failure of the inspiratory muscle pump; this seems implausible since no trend for PTPoes or PTPdi to fall during PPV exhaustive exercise was observed. The alternative would be that the ventilatory load progressively increases during exhaustive PPV-assisted exercise. This model would be consistent with progressive carbon dioxide production (and retention) consequent on the loss of oxidative capacity [30], which is a recognized feature of the peripheral myopathy associated with COPD. In this context, it is of interest that the two subjects whose performance showed the greatest improvement with PPV were the two making the greatest use of the (possibly redundant) abdominal muscles during the free walk.

In summary, a breath-by-breath analysis of the progression of respiratory muscle recruitment in patients with severe chronic obstructive pulmonary disease performing constant rate exhaustive treadmill exercise is presented. Inspiratory muscle recruitment reached a plateau early in exercise, but expiratory muscle recruitment and minute ventilation increase progressively. Inspiratory pressure support reduced both inspiratory and expiratory muscle use. The present data support the concept that the diaphragm in chronic obstructive pulmonary disease responds poorly to the demands imposed by exercise. They also highlight the variation in abdominal muscle use in chronic obstructive pulmonary disease, which presently remains unexplained.

\section{References}

1. Grassino A, Gross D, Macklem PT, Roussos C, Zagelbaum G. Inspiratory muscle fatigue as a factor limiting exercise. Bull Europ Pathophysiol Respir 1979; 15: 105111.

2. Bye PT, Esau SA, Levy RD, et al. Ventilatory muscle function during exercise in air and oxygen in patients with chronic air-flow limitation. Am Rev Respir Dis 1985; 132: 236-240.

3. Kyroussis D, Polkey MI, Keilty SEJ, et al. Exhaustive exercise slows inspiratory muscle relaxation rate in chronic obstructive pulmonary disease. Am J Respir Crit Care Med 1996; 153: 787-793.

4. Polkey MI, Kyroussis D, Mills GH, et al. Inspiratory pressure support reduces slowing of inspiratory muscle relaxation rate during exhaustive treadmill walking in severe COPD. Am J Respir Crit Care Med 1996; 154: $1146-1150$.

Table 3. - Pressure/time product (PTP) of oesophageal pressure (PTPoes) and PTP of transdiaphragmatic pressure (PTPdi) data at exercise cessation during exhaustive free and positive pressure ventilation-assisted walking

\begin{tabular}{|c|c|c|c|c|c|c|}
\hline \multirow[b]{2}{*}{ Patient No. } & \multicolumn{2}{|c|}{ Walk duration min } & \multicolumn{2}{|c|}{ PTPoes $\mathrm{cmH}_{2} \mathrm{O} \cdot \mathrm{s} \cdot \mathrm{min}^{-1}$} & \multicolumn{2}{|c|}{ PTPdi $\mathrm{cmH}_{2} \mathrm{O} \cdot \mathrm{s} \cdot \mathrm{min}^{-1}$} \\
\hline & Free & Assisted & Free & Assisted & Free & Assisted \\
\hline 7 & 6 & 15 & 349 & 169 & 270 & 185 \\
\hline 9 & 8 & 11 & 189 & 25 & 217 & 101 \\
\hline 10 & 10 & 18 & 301 & 83 & 272 & 72 \\
\hline 11 & 5 & 8 & 324 & 147 & 272 & 102 \\
\hline 12 & 5 & 14 & 374 & 244 & 263 & 105 \\
\hline Mean \pm SD & $6.8 \pm 2.2$ & $13.2 \pm 3.8$ & $307 \pm 72$ & $134 \pm 84$ & $259 \pm 24$ & $113 \pm 42$ \\
\hline
\end{tabular}


5. Similowski T, Yan S, Gauthier AP, Macklem PT, Bellemare F. Contractile properties of the human diaphragm during chronic hyperinflation. $N$ Engl J Med 1991; 325: 917-923.

6. Potter WA, Olafsson S, Hyatt RE. Ventilatory mechanics and expirtarory flow limitation during exercise in patients with obstructive lung disease. J Clin Invest 1971; 50: 910-919.

7. Suero JT, Woolf CR. Alterations in mechanical properties of the lung during dyspnea in chronic obstructive pulmonary disease. J Clin Invest 1970; 49: 747-751.

8. Petrof BJ, Calderini E, Gottfried SB. Effect of CPAP on respiratory effort and dyspnea during exercise in severe COPD. J Appl Physiol 1990; 69: 179-188.

9. Maltais F, Reissmann H, Gottfried SB. Pressure support reduces inspiratory effort and dyspnea during exercise in chronic airflow obstruction. Am J Respir Crit Care Med 1995; 151: 1027-1033.

10. Kyroussis D, Mills GH, Polkey MI, et al. Abdominal muscle fatigue after maximal ventilation in humans. $J$ Appl Physiol 1996; 81: 1477-1483.

11. Kyroussis D, Mills GH, Polkey MI, et al. Effect of maximum ventilation on abdominal muscle relaxation rate. Thorax 1996; 51: 510-515.

12. Hamnegard C-H, Wragg SD, Kyroussis D, et al. Diaphragm fatigue following maximal ventilation in man. Eur Respir J 1996; 9: 241-247.

13. Sassoon CS, Lodia R, Light RW, Mahutte CK. Maximum inspiratory muscle endurance capacity during resistive loading in chronic obstructive pulmonary disease. Respiration 1990; 57: 343-350.

14. Polkey MI, Kyroussis D, Hamnegard C-H, et al. Diaphragm performance during maximal voluntary ventilation in chronic obstructive pulmonary disease. $\mathrm{Am} \mathrm{J}$ Respir Crit Care Med 1997; 155: 642-648.

15. Polkey MI, Kyroussis D, Keilty SEJ, et al. Exhaustive treadmill exercise does not reduce twitch transdiaphragmatic pressure in patients with COPD. Am J Respir Crit Care Med 1995; 152: 959-964.

16. Polkey MI, Kyroussis D, Hamnegard C-H, Mills GH, Green M, Moxham J. Diaphragm strength in chronic obstructive pulmonary disease. Am J Respir Crit Care Med 1996; 154: 1310-1317.

17. Sassoon CSH, Light RW, Lodia R, Sieck GC, Mahutte $\mathrm{CK}$. Pressure-time product during continuous positive airway pressure, pressure support ventilation, and T-piece during weaning from mechanical ventilation. Am Rev Respir Dis 1991; 143: 469-475.

18. Bai T, Rabinovitch B, Pardy R. Near-maximal voluntary hyperpnea and ventilatory muscle function. $J$ Appl Physiol 1984; 57: 1742-1748.

19. Brochard L, Harf A, Lorino H, Lemaire F. Inspiratory pressure support prevents diaphragmatic fatigue during weaning from mechanical ventilation. Am Rev Respir Dis 1989; 139: 513-521.

20. Ninane V, Yernault JC, de Troyer A. Intrinsic PEEP in patients with chronic obstructive pulmonary disease. Role of expiratory muscles. Am Rev Respir Dis 1993; 148: 1037-1042.

21. De Troyer A, Leeper JB, McKenzie DK, Gandevia SC. Neural drive to the diaphragm in patients with severe COPD. Am J Respir Crit Care Med 1997; 155: 13351340.

22. Macklem PT, Gross D, Grassino A, Roussos C. Partitioning of inspiratory pressure swings between diaphragm and intercostal/accessory muscles. J Appl Physiol 1978; 44: 200-208.

23. Criner GJ, Celli BR. Ventilatory muscle recruitment in exercise with $\mathrm{O}_{2}$ in obstructed patients with mild hypoxaemia. J Appl Physiol 1987; 63: 195-200.

24. Suzuki S, Suzuki J, Ishii T, Akahori T, Okubo T. Relationship of respiratory effort sensation to expiratory muscle fatigue during expiratory threshold loading. Am Rev Respir Dis 1992; 145: 461-466.

25. Rahn H, Otis AB, Chadwick LE, Fenn WO. The pressurevolume diagram of the thorax and lung. Am J Physiol 1946; 146: 161-178.

26. Stubbing DG, Pengelly LD, Morse JLC, Jones NL. Pulmonary mechanics during exercise in subjects with chronic airflow obstruction. J Appl Physiol 1980; 49: 511-515.

27. O'Donnell DE, Webb KA. Exertional breathlessness in patients with chronic airflow limitation. The role of hyperinflation. Am Rev Respir Dis 1993; 148: 1351-1357.

28. Yan S, Kaminski D, Sliwinski P. Reliability of inspiratory capacity for estimating end-expiratory lung volume changes during exercise in patients with chronic obstructive pulmonary disease. Am J Respir Crit Care Med 1997; 156: 55-59.

29. Jubran A, Van de Graaf WB, Tobin MJ. Variability of patient ventilator interaction with pressure support ventilation in patients with chronic obstructive pulmonary disease. Am J Respir Crit Care Med 1995; 152: 129-136.

30. Maltais F, Simard A-A, Simard C, et al. Oxidative capacity of the skeletal muscle and lactic acid kinetics during exercise in normal subjects and in patients with COPD. Am J Respir Crit Care Med 1996; 153: 288-293. 